\title{
Metadiscourse in Academic Writing of Pre-University Arab Students at the International Islamic University Malaysia (IIUM)
}

\author{
Muhamad Khairul Zakaria ${ }^{1, *}$ and Faridah Abdul Malik ${ }^{2}$ \\ ${ }^{1}$ English Language Centre (ELC), Centre of Foundation and Liberal Education (PPAL), Universiti Malaysia Terengganu, Malaysia \\ ${ }^{2}$ English Language Division, Centre for Languages and Pre-University Academic Development (CELPAD), IIUM Malaysia
}

\begin{abstract}
There is lack of studies on the use of metadiscourse markers; especially amongst international students studying in Malaysia and Malaysia are receiving scores of international students particularly from the Middle East annually. This study involves a textual analysis of students' academic writing where the metadiscourse markers in 50 Arab IIUM students' academic texts were identified and analyzed. The findings of this study indicated that Arab writers had a greater inclination for the deployment of the interactive markers (Total counts $=919)$ than interactional ones (Total counts $=592$ ) as there was a higher percentage of interactive metadiscourse (60.8\%) usage than the interactional ones (39.2\%). It might be useful for English language teachers to integrate cultural considerations within their syllabus with regard to metadiscourse markers in order to prepare relevant materials based on their students' needs as well as to develop the students' awareness of the importance of these linguistic features.
\end{abstract}

\section{Introduction}

\subsection{Background of study}

Writing essays is an important part of a student's life at the university for the reason that they have to write essays for their assignments. The quality of the written assignments would have a significant influence on their academic achievement. Moreover, the capability to compose academic texts competently at institution of higher education is a practical anticipation to be grasped by the tertiary learners [1]. In order to compose a comprehensible writing, the learners need to employ appropriate metadiscourse markers within their written tasks. Tan and Wong (2014) mentioned that metadiscourse is a central semantic means that aids authors to navigate the movement of their written content as well as to address their standpoint to their readers [2].

According to Hyland and Tse (2004), the metadiscourse markers are important resources deployed to designate how the text is organized, to clarify difficult words and jargons for readers, and to put into code what rhetorical acts are being performed [3]. Competent employment of metadiscourse markers will make a text readable.

Thus, the knowledge of metadiscourse is frequently observed to be beneficial not only for students and the anticipated readers of the students' written works, but also for language instructors. Teachers can interpret their students' writing by looking at the students' deployment of metadiscourse. Consequently, the observation on the deployment of metadiscourse might assist the teachers to guide their students to be more thoughtful of the variances between students' national culture and the culture of the discourse or the community to which the text denotes [4].

\subsection{Statement of the problem}

Effective deployment of metadiscourse markers can be one of the means of enhancing the quality of academic essays written within academic circles [5]. Specifically, the utilization of metadiscourse markers were suggested to improve the writing quality [6], increase the readability [7], and build a relationship with the readers $[4,8]$. These features are very important in developing a good quality academic writing [2]. In fact, several studies have shown that the use of metadiscourse can improved the academic writing among students. For instance, a study done by $\mathrm{Lu}$ (2011) shows that metadiscourse has helped in improving the academic writing among the Chinese EFL students' in the pedagogical context of composition classrooms in China [9]. Such abundance of studies provide evidence of its prominence within the writing realm, predominantly in academic writing. Moreover, there is an increasing concern with the quality and standard of academic writing among university students especially concerning ESL students [10].

However, there is lack of studies on the use of metadiscourse markers, especially amongst international students studying in Malaysia. This is significant since higher education institutions in Malaysia are receiving scores of international students particularly from the Middle East annually. The study 
aimed to determine the forms and frequency of metadiscourse markers used in the academic essays written by these students.

\subsection{Research objective}

The significant of metadiscourse in academic writing prompts this research which attempts to determine the forms and frequency of metadiscourse markers used by Arab Pre-University writers in their opinion-based essays.

\subsection{Research Question}

In keeping with the aim of the study the following research question was addressed: RQ1 What are the forms and frequency of metadiscourse used in the opinion-based essays written by Arab Pre-University writers?

\subsection{Significance of the study}

Primarily, the study will cater to the teaching and learning need of IIUM's multi-national environment where the second biggest group of students is the Arabs who come second after the Malaysians. Besides, metadiscourse markers are important to the targeted groups which include the Arab students of English as ineffective deployment of metadiscourse in their academic writing will affect the quality of their writings. Thus, knowing about metadiscourse markers will assist the language instructors to increase the Arab students' language awareness and improve their writing ability. This is very significant in the case of the Arab students as higher education institutions in Malaysia are receiving scores of international students particularly from the Middle East every year.

\section{Materials and Methods}

\subsection{Research design}

This study involves a textual analysis of students' academic writing where the metadiscourse markers in Arab ESL students' academic texts were identified and analyzed.

\subsection{Participants}

A total of 50 Level 6 Pre-University Arab students from the Centre for Languages and Pre-University Academic Development (CELPAD), IIUM participated in this study.

English and Arabic are the two primary languages used for instructions in IIUM, depending on the specific programme of study. The CELPAD is responsible for ensuring that all IIUM students have a strong command of the languages required for their studies. Applicants wishing to pursue their studies in programmes with English as medium of instruction must present a score of 550 in the Test of English as a
Foreign Language (TOEFL) or Band 6.0 in the International English Language Testing Service (IELTS) (Academic) with a minimum Band of 5.5 for each of the Skills - Writing, Reading, Listening/ Speaking (WRLS).

Alternatively, they may sit for the IIUMadministered English Placement Test (EPT) and obtain a minimum Band of 6.0 to fulfill the English language requirement. Applicants who are unable to submit satisfactory results in any of the above tests may take up language proficiency courses at the University to fulfill the admission requirements. ("Centre for Languages and Pre-University Academic Development," n.d.)

\subsection{Data collection}

Opinion based essays written by the students' in the English Placement Test were analysed to study the deployment of metadiscourse markers by the PreUniversity Arab students. The opinion based composition was the kind of essay written and was selected for the reason that the academic written text is opinion centered where the deployment of metadiscourse was anticipated to be apparent in such text category (Silver, 2003). The essays were written 50 Arab ESL learners who were registered in the intensive English course at CELPAD. All these essays were given a score of band 6 which means that the writers were considered to have acquired the minimum band of proficiency in writing and can proceed to their faculty programmes.

\subsection{Textual analysis}

The essays were analyzed by means of the subsequent stages: categorising, ordering, and inferring. To start with, the metadiscourse markers of ESL students' academic writings were identified. Next, the markers were categorized into either interactive or interactional. The interactive metadiscourse markers were then further categorised into code glosses, transitions, endophorics, frame markers or evidentials; while the interactional metadiscourse markers were then further categorised into self-mentions, booster, attitude markers, engagement markers, or hedges. This inclusive organisation is grounded on Hyland's taxonomy [5]. Then, the researcher identified the interactive and interactional metadiscourse markers that were dominantly employed by the learners.

To achieve a higher reliability, the whole corpora were manually analysed word for word because computer-assisted analysis faces the risk of assuming external reference items as metadiscourse and could damage the validity of research [11]. All the procedures were carried out separately by another rater, in order to countercheck as well as to uphold impartiality in the process of detailing of the deployment of metadiscourse markers within the selected corpora. The second rater received sufficient training in doing the task. During the training session, the researcher and the second rater comprehensively 
discussed any confusion and incongruity with regard to the metadiscourse markers. Series of exercises using samples from the participants' writings were endured by both researchers to make sure that both raters comprehended and perceived the metadiscourse markers in a similar fashion. There was an agreement found between the researcher and the second rater with reference to the frequency count of metadiscourse markers in the students' academic essays.

After the collection of data, the total amount of metadiscourse markers was determined. The total amount of metadiscourse markers in the academic essays written by the Arab Pre-University writers was tallied and checked individually. This presented the answer to RQ1 which aimed to determine the frequency and forms of metadiscourse markers used in the academic essays written by the Arab Pre-University students.

\subsection{Theoretical framework}

The framework used in this study to investigate metadiscourse usage in academic writing is the International Model of Metadiscourse which was developed Hyland [4]. Even though researchers dealing with metadiscourse have respectively fabricated their personal classification of metadiscourse [12-14], the classification made by Hyland was selected as the main framework over the varieties of models and to be the main outline for this research for the reason that the classification is comprehensive as well as concise.

As illustrated in Table 1, the interactive metadiscourse, which is the first dimension of Hyland's model, permits authors to compose a unified as well as a comprehensible writing. The subcategories of the interactive dimension are endophoric markers, code glosses, transition markers, evidential, and frame markers.

The interactional category is another element of metadiscourse. The main purpose of the interactional dimension is to enable the authors to deliver their reactions or sentiments in the intended parts of the writings as well as to construct a particular relationship with the person who reads the text. The interactional metadiscourse sub-categories are engagement markers, hedges, attitude markers, self-mentions and boosters.

Table 1. An interpersonal model of metadiscourse [4]

\begin{tabular}{|c|c|c|}
\hline Classification & Function & Instances \\
\hline $\begin{array}{l}\text { Interactive } \\
\text { Metadiscourse }\end{array}$ & Guide and support the reader through the writing & \\
\hline Transitions & $\begin{array}{l}\text { express semantic connection between focal } \\
\text { phrases }\end{array}$ & $\begin{array}{l}\text { and / thus / but / in } \\
\text { addition }\end{array}$ \\
\hline Frame markers & $\begin{array}{l}\text { denote to text stages acts, discourse, or } \\
\text { sequences }\end{array}$ & $\begin{array}{l}\text { my purpose here is to/ to } \\
\text { conclude/ finally }\end{array}$ \\
\hline $\begin{array}{l}\text { Endophoric } \\
\text { markers }\end{array}$ & $\begin{array}{l}\text { indicate statistics and data in other sections of the } \\
\text { writing }\end{array}$ & $\begin{array}{l}\text { see Fig / noted above/ in } \\
\text { section } 2\end{array}$ \\
\hline Evidentials & refer to source of information from other texts & $\begin{array}{l}(\mathrm{X}, 1990) \text { / Y states / } \\
\text { according to Z }\end{array}$ \\
\hline Code glosses & $\begin{array}{l}\text { help readers grasp functions of ideational } \\
\text { material }\end{array}$ & $\begin{array}{l}\text { in other words/ namely/ } \\
\text { e.g./ such as }\end{array}$ \\
\hline $\begin{array}{l}\text { Interactional } \\
\text { Metadiscourse } \\
\end{array}$ & Involve the reader in the writing & \\
\hline Hedges & $\begin{array}{l}\text { withhold writer's full commitment to } \\
\text { proposition }\end{array}$ & $\begin{array}{l}\text { possible / about / might / } \\
\text { perhaps }\end{array}$ \\
\hline Boosters & $\begin{array}{l}\text { accentuate writer's certainty or force in } \\
\text { proposition }\end{array}$ & $\begin{array}{l}\text { definitely/ it is clear } \\
\text { that/ in fact }\end{array}$ \\
\hline Attitude markers & express writer's attitude to proposition & $\begin{array}{l}\text { I agree/ surprisingly/ } \\
\text { unfortunately }\end{array}$ \\
\hline $\begin{array}{l}\text { Engagement } \\
\text { markers }\end{array}$ & $\begin{array}{l}\text { explicitly refer to or build relationship } \\
\text { with reader }\end{array}$ & $\begin{array}{l}\text { note that/ you can see } \\
\text { that/ consider }\end{array}$ \\
\hline Self-mentions & explicit reference to author(s) & $\mathrm{I} / \mathrm{my} / \mathrm{our} / \mathrm{we}$ \\
\hline
\end{tabular}

\section{Results}

Research question 1: what are the forms and frequency of metadiscourse used in the opinion-based essays written by Arab pre-university writers?

\subsection{Interactive metadiscourse}

Figure 1 shows the frequency of the different subcategories within the interactive metadiscourse among the Arab pre-university writers in their academic essays. The total number of occurrences of the deployment of interactive metadiscourse in the academic texts produced by the Arab students was 919 . As can be seen from Fig. 1, the highest usage is for Transition (583) while the second and third highest frequency are for Frame markers (220) and Code glosses (103) correspondingly. Additionally, the fourth highest frequency is for Evidentials (10) while the least used interactive metadiscourse marker is Endophoric marker (3). 
Similar to the Malaysian writers' usage, Transitions, which function to mark semantic relation between main clauses in the Arab students' text, were actually the most noticeable interactive metadiscourse feature. Furthermore, the lower density of endophoric markers and evidentials shows that the Arab students did not have sufficient information to make a mention to facts in other sections of the writing. The third least frequently applied interactive metadiscourse markers in the students' essays, Code glosses, might be owed to the fact that the students habitually undertook that their intentional readers already acquired sufficient contextual knowledge to comprehend and appreciate whatever messages they were conveying in the texts.

Examples of interactive markers used by the Arabs students are given in (1) - (5).

(1) Transitions “...some people do not do well in their studies but they have different hobbies and skills that can make them to have their own business..." (Arab student, ID: 72)

(2) Frame markers "Secondly, there is no conclusive doubt that communication is an important factor in education." (Arab student, ID: 2)

(3) Endophoric markers "In addition to the above, this helps teach ones child to respect elders, while offering a liner emotional support..." (Arab student, ID: 10)

(4) Evidentials "For instance, in a study conducted by Lawa University, researchers found that almost all youngsters consider their parents as models in their lives." (Arab student, ID: 6)

(5) Code glosses "In conclusion, while being a child's best friend is important, yet it is only a part of a greater picture, i.e. parenthood." (Arab student, ID: 10)

The subsequent section will present the findings on the usage of interactional metadiscourse markers among the Arab Pre-University writers in their essays.
Figure 2 shows the frequency of the different subcategories of the interactional metadiscourse among the Arab pre-university writers in their academic essays. The total number of occurrence of interactional metadiscourse in the academic texts produced by the Arab students was 592.

From the data in Fig. 2, it can be seen that by far the highest usage is for Self mentions (276) while the lowest usage is Engagement markers (45). The second highest usage is for Hedges (105) and followed by Attitude markers (87) and Boosters (79). Arab students appeared to focused on self-mentions more, while

showing a comparatively lower reliance on openly constructing relationship with or communicating to their intentional reader since they utilized fewer boosters in their texts. The examples of Interactional markers used by the Arab students are given in (1) (5).

(1) Hedges "Regarding this issue, parents may provide advises when their children have emotional problem." (Arab student, ID: 7)

(2) Boosters "It is an obvious fact that children are born to both father and mother and their role are undeniable." (Arab student, ID: 7)

(3) Attitude markers "However, unfortunately this group has been showing a bad image about Islam in all over the world." (Arab student, ID: 14)

(4) Engagement markers "Lastly, due to the above reason I believe that with proper implementation of this approach to parenting, friendship with the children is the best method to raise children with..." (Arab student, ID: 8)

(5) Self-mentions "Finally, we can conclude this argument by saying that teachers gave us a lot, and we should not pay back by ignoring their importance, advancement in educational..." (Arab student, ID: 3)

The results indicate that interactive metadiscourse markers were used more by the Arab students than interactional resources.

\subsection{Interactional metadiscourse}




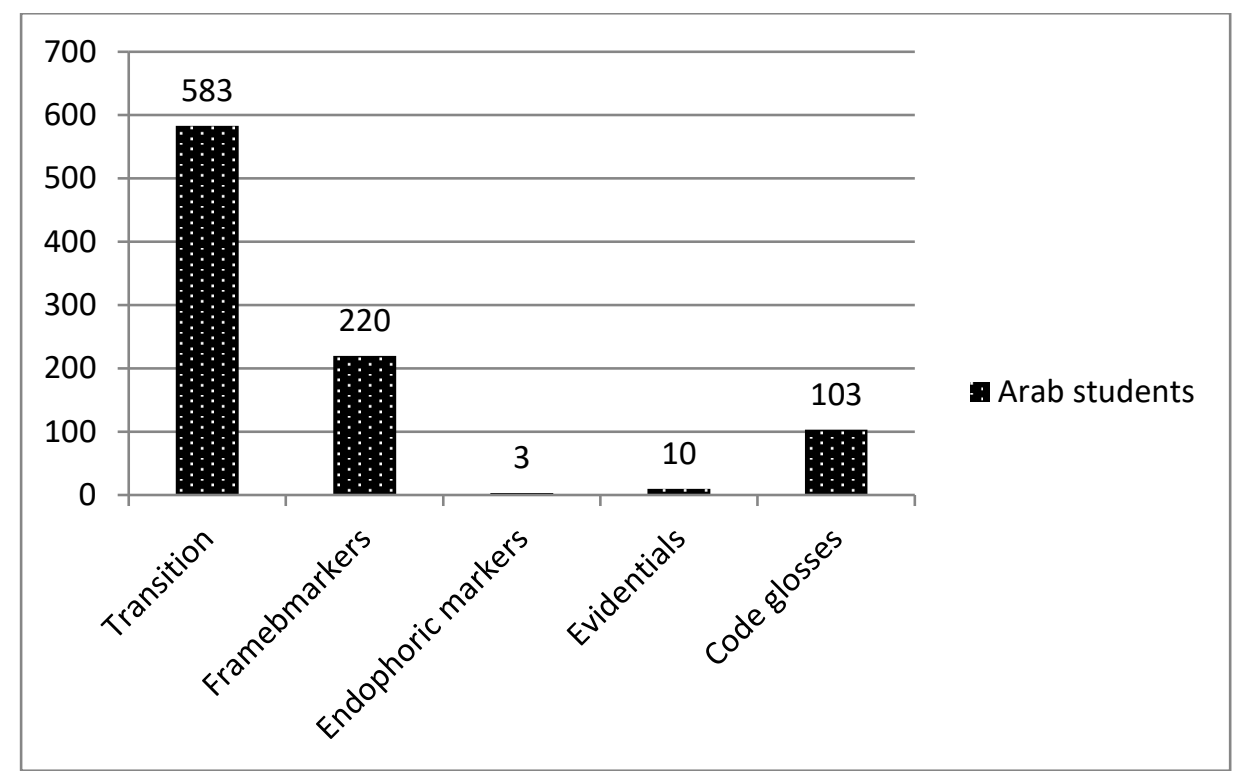

Fig. 1. Frequency of use of the different sub-categories within the interactive metadiscourse among the Arab pre-university writers. (Interactive metadiscourse markers)

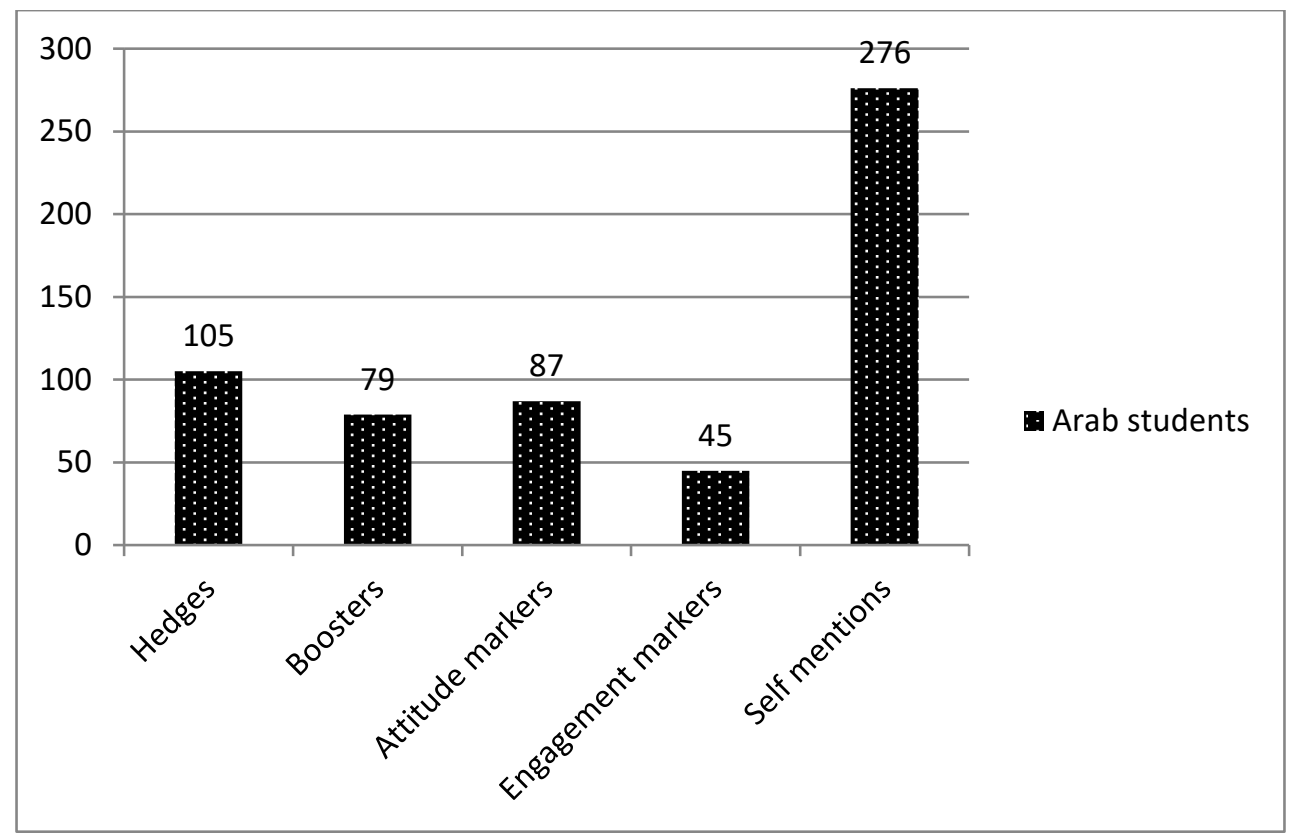

Fig. 2. Frequency of use of the different sub-categories within the interactional metadiscourse among the Arab pre-university writers. (Interactional metadiscourse markers)

\section{Discussion}

The total occurrence of metadiscourse in the academic texts produced by the Arabs students was 1511. Another important finding was that Arab pre-university writers had a greater inclination for the deployment of the interactive markers than interactional ones as there was a higher percentage of interactive metadiscourse usage than the interactional ones among the students.

These results are in agreement with previous findings [15-16] which showed that undergraduate students have greater tendency in deploying the interactive metadiscourse (also known as textual metadiscourse) than using the interactional 
metadiscourse (interpersonal metadiscourse). One dominant cause might be due the culture differences demonstrated in the students' writing conventions. In the same vein, the result for the Arab students is in agreement with Faghih and Rahimpour's findings which showed that interactive metadiscourse (those markers which help to guide the reader through the text) were deployed considerably greater in comparison to interactional metadiscourse (those metadiscourse markers which include the person who reads in the text) by Iranians as non-natives of English within their research articles compositions. In addition to the main reason of different socio-culture background amongst the ESL writers, Faghih and Rahimpour provided another possible explanation that the ESL students are more familiar with the usage of certain markers under the interactive dimension; for instance, frame markers, transition markers, as well as code glosses [17].

The result concerning the high rate of deployment of interactive metadiscourse, in excess of the interactional markers was also found to be in agreement with the result described in a study conducted by Salek [8] on academic synopses written in English by native authors. This consistency evidently advocates the significance of textual metadiscourse (also known as interactive metadiscourse) components in academic essays in comparison to the interactional ones. Furthermore, the different usage of metadiscourse might be due to the authors' linguistic customs and norms attained during their discrete involvements in their respective writing courses. To put it differently, the academic authors from diverse cultural upbringings and backgrounds may have established fundamentally distinctive writing styles well as distinct modes of interaction due to training which they received from their respective instructors. Consequently, the diversity in the individual writing styles among the writers of different backgrounds may be demonstrated by the construction as well as conceptualization of discrete worldviews which are rooted in a specific culture of a specific discourse cluster [17].

The essays used for text analysis in this current study were opinion-based academic essays. The essays required the students to express their opinion towards an issue. In this type of composition, there are usually more transition (for instance, but; in addition; thus; and) and frame markers (for instance, finally; my purpose is; to conclude) used in directing the target reader from end to end of the writing while more hedges (for instance, possible; perhaps; might; about) boosters (for instance, in fact; definitely; it is clear that), self-mentions (for instance, my; we; I; our; me), attitude markers (for instance, unfortunately; surprisingly; I agree), and engagement markers (for instance, you can see that; note; consider) will be used to involve the reader in the text. It is expected that in an opinion-based essay, more interactive markers should be involved to provide guidance in order to assist the intentional reader to read the written text effortlessly, to manifest semantic relation concerning key passages, to denote discourse items, orders, as well as writing phases, and to provide support for the person who reads to comprehend meanings of ideational material within the written text.

\section{Conclusion}

The main objective of this research was to determine the deployment of metadiscourse markers in the academic texts produced by Arab Pre-University writers. The examination of the metadiscourse employed by these ESL students has offered interesting findings and thought-provoking insights. One of the significant findings that has emerged from this study is that Arab pre-university writers had a greater inclination for the deployment of the interactive markers than interactional ones as there was a higher percentage of interactive metadiscourse usage than the interactional ones among the students. Culture differences demonstrated in the students' writing conventions may be the reason for the differences.

Contribution to body of knowledge. The findings of this research offer further understandings for the use of metadiscourse in the area of text analysis. Moreover, not many academics connected with the field of linguistics and English as a second language, had comprehensive knowledge on the ways metadiscourse markers are realized in English academic written texts. This study extends our knowledge of the use of metadiscourse among the Arab students. This finding is important as it will serve as a source that students as well as the English language educators can refer to and learn about the types of metadiscourse markers which are scarce in the students' writings (such as, endophoric markers and evidentials) and to be deployed more frequently in their composition so that it will enhance their quality of academic writing.

A key strength of the present study is that it enhances our understanding of the dissimilar deployment of metadiscourse markers among the Arab students' in their academic writing. This is important as higher education institutions in Malaysia are receiving higher intake of international students particularly from the Middle East. Therefore, it is crucial to take care of the education standards especially in the English language in order to sustain the credibility of the Malaysian higher education institutions. By having a text-analysis instrument (i.e. metadiscourse), it will help English language educators to detect any rhetorical variations as well as limitation in written essays quickly and improve the inadequacies in English academic writing among the students especially those from the non-native English countries. Hence, it will address future needs of these students especially in relation to their written proficiency.

Limitations and future studies. A limitation of this study is that it was carried out among the Arab students only. It did not include any other international students. As a result, the generalisability is not conceivable to other ESL students. Also, the present study was restricted to pre-university students; that it did not include the whole array of students' groups; under 
graduates and post graduates. Also, the scope of the study was limited only to the deployment of metadiscourse markers in academic writing, specifically the opinion based essays.

Although it is possible that proficiency could be accountable for the varieties of metadiscourse patterns among the students as mentioned in some of previous studies [1-2], this cannot be determined since generally most of the studies did not state the level of proficiency of the writers who wrote the texts that they examined. Also, this is not the focus of this study as the participants' proficiency level was presumed to be similar, that is within satisfactory proficiency level.

More research is required to determine the effectiveness of this text-analysis instrument (i.e. metadiscourse) in the future. It is recommended that further research can involve comparisons with other international students who are studying in Malaysia. This will profit Malaysian higher education institutions. In addition, the learners can be more conscious with the deployment of metadiscourse markers in English for academic writing.

\section{References}

1. B. Giridharan, Identifying Gaps in Academic Writing of ESL Students. US- China Education Review, (Curtin University, Miri, Malaysia, 2012)

2. H. Tan, B. E. Wong, English Language Teaching, 7(7), (2014)

3. K. Hyland, P. Tse, App. Ling., 25 (2), 156-177, (2004)

4. K. Hyland, Metadiscourse: Exploring Interaction in Writing (London, 2005)
5. Continuum, J. App. Res. Eng., 1(2), 37-44, (2012)

6. P. M. Letsoela, Int. J. Ling., 5(6), 138-153, (2014)

7. W. Shi, J. Han, Eng. Lang. Teach., Vol. 7, No. 11.,151-158, (2014)

8. Z. Zarrati, R. M. Nambiar, T. N. R. T. M. Maasum, Effect of Metadiscourse on Reading Comprehension of Iranian EFL Learners. $3 L$ : Language, Linguistics, Literature, 20(3), pp 27-38 (2014)

9. M. Salek, Journal of Language Sciences \& Linguistics 2 (3), 55-66 (2014)

10. L. Lu, Metadiscourse and genre learning: English argumentative writing by Chinese undergraduates (The University of Hong Kong, 2011)

11. H. J. S. Abbas, Acta Ling., Vol. 5, (2011)

12. G. Mehrnaz, T. Ghaffar, S. Nasrin, Euro. J. Eng. Lang. L. Stud., 2(2), 1-41 (2014)

13. A. Crismore, Metadiscourse: What It Is and How It Is Used in School and Non-School Social Science Texts. Technical Report 273, (University of Illinois: Centre for the Study of Reading, 1983)

14. N. Fairclough, Discourse and social change (Cambridge, England: Polity Press,1992)

15. W. J. Vande Kopple, J. Eng. Aca. Pur., 20, 114124 (2002)

16. A. Nor Hafizah, E. O. Luyee, J. I. Gabriel R. K. Seyed Ali, Eng. Lang. Teach., 16(9), (2013)

17. E. Faghih, S. Rahimpour, Ling, 1, 92-107, (2009)

18. H. Shokouhi, A. Talati Baghsiahi, Poznan Stud. Cont. Ling, 45 (4), 549-568 (2009)

19. M. Silver, J. Eng. A. Pur., (4), 359-374 (2003) 